\title{
Knowledge of Mothers About Puberty Health in Girls: A Survey in the Center of Iran
}

\author{
Elham Naghshineh ${ }^{1}$, Parastoo Golshiri² ${ }^{*}$, Zahra Hadi Sichani ${ }^{2}$ \\ 'Department of Gynecology, School of Medicine, Isfahan University of Medical Sciences, Isfahan, Iran \\ ${ }^{2}$ Department of Community Medicine and Family Physician, School of Medicine, Isfahan University of Medical \\ Sciences, Isfahan, Iran \\ Corresponding Author: Parastoo Golshiri, MD, MPH, Associate Professor, Department of Community Medicine and \\ Family Physician, School of Medicine, Isfahan University of Medical Sciences, Isfahan, Iran. Tel: +98-3136693985, \\ Email: golshiri@hlth.mui.ac.ir
}

Received May 19, 2017; Accepted August 14, 2017; Online Published September 9, 2017

\begin{abstract}
Introduction: Maintaining and promoting health during puberty is among the most important educational matters and demands sufficient awareness. This is while, the knowledge of parents in this regard and its problems is not enough. Therefore, the present study investigated the knowledge of mothers regarding their daughters' puberty health.

Methods: In this cross-sectional study, the mothers of 200 girls' aged 10-15 years and living in the center of Iran were chosen using the random sampling method and surveyed using a researcher-made questionnaire. The reliability of the questionnaire was calculated using Cronbach alpha (0.844).

Results: The mean score of mother's knowledge regarding social puberty was $83.61 \pm 15.38$, regarding psychological puberty was $79.94 \pm 20.20$, regarding physical puberty was $72.22 \pm 18.00$, and regarding nutrition during puberty was $76.55 \pm 17.60$. There was a direct correlation between mother's education and mother's knowledge scores $(P<0.001, r=0.285)$, but no significant correlation was seen between mother's knowledge and mother's age or father's job.

Conclusion: The results indicated that mothers are well-informed of their daughters' experience with puberty. Since mothers are considered the educational source for their daughters in most cases, their level of knowledge is important.

Keywords: Puberty, Knowledge, Mothers, Girls, Adolescent, Health, Iran
\end{abstract}

Citation: Naghshineh E, Golshiri P, Hadi Sichani Z. Knowledge of mothers about puberty health in girls: a survey in the center of Iran. Int J Travel Med Glob Health. 2017;5(3):102-106. doi:10.15171/ijtmgh.2017.21.

\section{Introduction}

At the end of childhood, a person enters a new phase known as juvenility, the conditions of which are completely different from those of the previous stage. The maturation process is the most important change during adolescence. It has a special importance and is referred to as a milestone in the lives of young people. ${ }^{1}$ The fate and future of people are tied to logical decisions and dealing properly with the changes of this life period. ${ }^{2}$ Puberty causes physiological, biological, social, and psychology changes., ${ }^{3,4}$ The infrastructure of adult life is underpinned in this period, and when it is not paid the necessary attention, many psychological problems, infectious diseases, failed marriages, and premature and risky pregnancies can occur. ${ }^{1}$

According to the 2012 census, the age group of $10-19$ years constitutes $16.34 \%$ of Iran's total population. ${ }^{5}$ Maintaining and improving puberty health is one of the most important educative issues in this period. Enough knowledge of both the teenager' parents and school authorities about the issues ahead in this period is absolutely necessary. Some studies have reported that Iranian adolescents have insufficient knowledge about puberty. A research conducted in Tabriz, Urmia, and Ardebil on 2700 students reported that only $40 \%$ of adolescents have sufficient knowledge about puberty. ${ }^{6}$

The Eastern Mediterranean Region office of the World Health Organization knows that applying principles and effective strategies for the health education of adolescents is necessary and suggests that correct and accurate information about reproductive sanitation and sexual puberty be provided to children according to their age levels through parents, teachers, health providers, religious organizations, and leaders. ${ }^{7}$ The results of multiple studies have shown that parents play the most important role in transferring this information to their children. According to various sources, research on

Copyright $\odot 2017$ The Author(s). This is an open-access article distributed under the terms of the Creative Commons Attribution License (http:// creativecommons.org/licenses/by/4.0), which permits unrestricted use, distribution, and reproduction in any medium, provided the original work is properly cited. 
girls has revealed that girls' mothers are the most important source of information transmission regarding issues related to the period of menstruation to their girls (58\%), followed by family and friends (27.6\%), sanitation officials (12.4\%), and books, newspapers, and magazines (2\%). ${ }^{8}$ One study found that mothers considered it their duty to provide information to their girls regarding puberty and emphasized menstruation education, compliance with legal issues, and subtle education on sexual issues. ${ }^{9}$ In their study, Nouri and Merghati khoie indicated that participant adolescents considered the affecting factors to promoting puberty health to be their parents in the first stage, followed by their teachers and cinematic movies. ${ }^{10}$ Unfortunately, under the pretext of shame or modesty or in neglect of their child's development and needs, many parents forget this responsibility or leave it to teachers. ${ }^{11}$ The results of another study in Iran showed that girls' level of knowledge about puberty, proper sanitation, and behaviors associated with this phenomenon is much lower than expected due to the lack of correct transmission of information from parents to the girls. ${ }^{12}$ One of the challenges associated with adolescent health education for adolescent girls is the lack of sources of information regarding teenage years for mothers. ${ }^{13}$

Because of the importance of the parents' role in the education of adolescents regarding puberty sanitation, the knowledge of mothers regarding puberty and its health issues is very important. Regional, cultural, and geographical variations are effective on people's knowledge. The current study aimed to assess mother's knowledge regarding puberty health in order to better plan for interventions and necessary actions by the health system toward the empowerment of families in this issue.

\section{Methods}

\section{Setting}

This is a cross-sectional study. After obtaining approval from the University Ethics Committee, about 200 mothers of female students between the ages of 10-15 years and living in the center of Iran were selected in 2014-2015. Inclusion criteria was consenting to participate in the study and having the ability to complete the questionnaire. Mothers who completed less than $90 \%$ percent of the questionnaire were excluded. The total number of schools in the study region was 9; four different geographical parts of the region were considered, and, using the random sampling method, 1 school was chosen from each part. Then, 2 classes were randomly selected from every school, and all students from every class were entered into the study. The questionnaire was given to literate mothers of participating students.

\section{Gathering Data Method}

To determine maternal knowledge of the puberty experience, a structured questionnaire was made by the researchers. The questionnaire had 2 sections. The first section contained questions regarding participant demographics, and the second part contained questions on 4 dimensions of puberty health (physical, nutritional, social, and psychological). Each dimension contained 6 to 8 multiple choice questions (with 4 options). The questionnaire was given to 10 mothers. Based on the feedback given, the necessary changes were made to improve the clarity of the questions. An expert panel (including an epidemiologist, a gynecologist, a community medicine specialist, and a psychiatrist) determined the face and content validity of the questionnaire, and all items were assessed and edited based on their comments. The reliability of the questionnaire was calculated using Cronbach alpha (0.844). To classify the level of knowledge, 100 questions were asked. Scores of 1 to 33 indicated weak knowledge, 34 to 66 indicated moderate knowledge, and 67 to 100 indicated good knowledge. After obtaining approval from the Isfahan Medical Science University Ethics Committee, the literate mothers were invited to the school with the coordination of school managers. The researchers explained the project's aims and methods to the mothers and asked them to complete the questionnaire. The participants were assured of the confidentiality of their information and were educated on how to complete the questionnaire.

Data Analysis

SPSS software version 20 was used to analyze the data in this study. Comparison of means was performed using the $t$ test and analysis of variance (ANOVA), and relationships between knowledge level and quantitative variables were determined using the Pearson correlation coefficient. Qualitative variables had a confidence coefficient of $95 \%$ using Spearman test.

\section{Results}

In this study, 167 of the 200 mothers invited to participate responded completely. The mothers' ages ranged between 28 and 52 years; the average age was 36.51 with a standard deviation of 4.9. Most mothers had a primary level education, and most fathers had a secondary level education. Most mothers were housekeepers, and most fathers were selfemployed (Table 1).

In this study, mothers scored highest on knowledge of social puberty and lowest on knowledge of physical puberty (Table 2).

Regarding the different issues of puberty, $86.4 \%$ of mothers had good knowledge, $13 \%$ had moderate knowledge, and $0.6 \%$ had poor knowledge (Table 3 ).

Statistically, the scores were distributed normally, and Pearson correlation coefficients showed that mother's age and the number of other girls in the family at the age of puberty or older had no significant relationship with mother's knowledge $(P>0.0 .5)$ (Table 4).

Results of the analysis of variance test indicated that there was no significant relationship between mother's knowledge score and mother's job. Moreover, there was no significant correlation between mother's overall knowledge and father's job $(P=0.267)$. Conversely, the test results revealed that mother's knowledge score regarding physical puberty had a significant relationship with father's job $(P=0.02)$.

Spearman correlation coefficients showed that mother's education was correlated with her knowledge score $(P<0.001$, $r=0.285)$, but level of education did not have a correlation 
Table 1. Distribution of Job and Education in Mothers and Fathers

\begin{tabular}{llc}
\hline Variable & Groups & Percent \\
\hline \multirow{3}{*}{ Mother's education } & Primary school & 32.8 \\
& Secondary school & 28.2 \\
& High School diploma & 28.7 \\
& University degree & 10.4 \\
& Illiterate & 2.4 \\
& Primary school & 34.5 \\
Father's education & Secondary school & 37 \\
& High School diploma & 14.5 \\
& Academic & 11.5 \\
& Housekeeper & 88.3 \\
Mother's job & Practitioner & 11.7 \\
& Self-employed & 35.2 \\
& Employee & 12 \\
& Driver & 9.9 \\
& Retired & 3.5 \\
& Farmer & 5.6 \\
& Laborer & 33.8 \\
\hline \multirow{3}{*}{ Father's job } & &
\end{tabular}

Table 2. Mean Scores of Mother's Knowledge in the Scope of Physical, Nutritional, Psychological, and Social Puberty

\begin{tabular}{lc}
\hline Scope of Knowledge & Mean \pm SD \\
\hline Mother's knowledge of physical puberty & $72.22 \pm 18.00$ \\
Mother's knowledge of nutrition in puberty & $76.55 \pm 17.60$ \\
Mother's knowledge of social puberty & $83.61 \pm 15.38$ \\
Mother's knowledge of psychological puberty & $79.94 \pm 20.20$ \\
Total & $78.17 \pm 12.32$ \\
\hline
\end{tabular}

with knowledge score regarding social and psychological maturation (Table 5). The Spearman correlation coefficient showed that father's education had a significant correlation with mother's knowledge score about physical maturation $(P<0.004, \quad r=0.223)$.

\section{Discussion}

This study sought to assess the knowledge level of mothers of females between the ages of 10 and 15 years regarding the physical changes occurring during puberty, nutrition during puberty, social puberty, and psychological puberty. This study further assessed the relationship between knowledge and variables such as mother's age, number of girls in the family who previously reached puberty, mother's education, father's education, mother's job, and father's job. Overall, the knowledge of mothers regarding the experience and hygiene of puberty was good according to the findings of this study, and most mothers had more knowledge in the scope of social puberty.

Few studies have investigated mother's knowledge of puberty in Iran; yet, the most important source for puberty health information for adolescents is the family. Although each family member has a role in educating girls about the issues of puberty, mothers play a more important role in teaching their adolescents health behavior. ${ }^{14}$ The knowledge, attitude, and even the behavior of students in the mental and physical aspects of puberty health are better than in previous decades, because the knowledge of mothers has improved. ${ }^{15}$ In one study that used peer group education, communication between mothers and their daughters was improved, and adolescents were empowered. ${ }^{10}$

In this study, mother's education had a direct relationship with mother's knowledge score. In a study by Najafi et al, a correlation was seen between maternal education level and mother's knowledge about puberty health. ${ }^{15}$ Karimi conducted a study in Tehran on the effects of the education of mothers on attitudinal, emotional, and behavioral issues in puberty. Their results showed that education level has a direct effect on mother's attitude. ${ }^{16}$ Poushaneh et al reported a significant relation between maternal education and knowledge level as well as the performance of students in the area of health. ${ }^{17}$ In this respect, Malek Afzali et al in Semnan showed that mother's education could play an important role

Table 3. Distribution of Mother's Knowledge Scores in the Scopes of Physical, Nutrition, Psychological, and Social Puberty

\begin{tabular}{lccccc}
\hline Mother's Knowledge Level & $\begin{array}{c}\text { Overall Knowledge } \\
\text { No. (\%) }\end{array}$ & $\begin{array}{c}\text { Physical Puberty } \\
\text { No. (\%) }\end{array}$ & $\begin{array}{c}\text { Nutrition in Puberty } \\
\text { No. (\%) }\end{array}$ & $\begin{array}{c}\text { Social Puberty } \\
\text { No. (\%) }\end{array}$ & $\begin{array}{c}\text { Psychological Puberty } \\
\text { No. (\%) }\end{array}$ \\
\hline Weak & $1-33$ & $1(0.6)$ & $2(1.1)$ & $3(1.7)$ & $2(1.1)$ \\
Moderate & $34-66$ & $23(13)$ & $33(18.6)$ & $(29.4) 52$ & $20(11.3)$ \\
Good & $67-100$ & $153(86.4)$ & $142(80.2)$ & (68.9) 122 & $156(88.1)$ \\
\hline
\end{tabular}

Table 4. Pearson Correlation Coefficient Between Maternal Age and Numbers of Other Girls in the Family at Puberty Age or Older, and The Knowledge Level of Mothers of Female Students Aged 10-15 Years Old

\begin{tabular}{lccc}
\hline \multirow{2}{*}{ Scope of Knowledge } & Number of Girls Who Have Reached Puberty & \multicolumn{1}{c}{ Mother's Age } & $\boldsymbol{P}$ \\
\cline { 2 - 4 } & $\boldsymbol{P}$ & $\boldsymbol{r}$ & -0.106 \\
\hline Physical puberty & 0.169 & -0.043 & 0.407 \\
Nutrition & 0.583 & 0.093 & 0.056 \\
Social puberty & 0.229 & 0.035 & 0.058 \\
Psychological puberty & 0.651 & -0.009 & 0.870 \\
Total & 0.903 & & 0.146 \\
\hline
\end{tabular}


Table 5. Relationship Between the Literacy of Parents and the Knowledge Score of Mothers of Female Students Aged 10-15 Years Regarding Physical, Nutrition, Psychological, and Social Puberty

\begin{tabular}{lcccc}
\hline \multirow{2}{*}{ Scope of Knowledge } & \multicolumn{2}{c}{ Mother's Education } & \multicolumn{2}{c}{ Father's Education } \\
\cline { 2 - 5 } & $\boldsymbol{P}$ & $\boldsymbol{r}$ & $\boldsymbol{P}$ & $\boldsymbol{r}$ \\
\hline Physical puberty & 0.001 & 0.326 & 0.004 & 0.223 \\
Nutrition & 0.008 & 0.202 & 0.320 & 0.078 \\
Social puberty & 0.149 & 0.110 & 0.685 & 0.032 \\
Psychological puberty & 0.159 & 0.107 & 0.777 & 0.022 \\
Total & 0.001 & 0.285 & 0.097 & 0.130 \\
\hline
\end{tabular}

in the ability of mothers to transfer the necessary training to their girls. Therefore, strengthening the relationship between mother and teenage daughter and eliminating obstacles to the expression of subjects regarding puberty or the incuriosity of mothers about the consequences of its healthy results must be included in any training program for mothers. Mothers must be familiar with how to acquire the trust and friendship of their girls in a convenient and friendly way. ${ }^{18}$ Kazemi, who noticed the impact of family variables on the knowledge of secondary school female students about puberty health, showed that there is a significant relation between parents' education and the knowledge level of students about puberty health. However, they did not find a relationship between girl's knowledge and mother's job. ${ }^{19}$

In this study, no significant correlation was seen between the overall score of mothers with father's job, but the mother's knowledge score in physical puberty had a direct correlation with father's job. Karimi showed that mother's education had a direct relationship with mother's attitude. ${ }^{16}$

\section{Conclusion}

Although the results of this study showed that mothers' knowledge about their girls' puberty experience was good, since the mother is a source of training in most cases, informing and training mothers are necessary. Most studies in Iran have investigated student knowledge about sanitation and issues of puberty; fewer studies have assessed the knowledge of mothers. Studies have shown that the mother is the most important and main educational source for adolescents, especially daughters. If a mother's knowledge is insufficient, adolescents are not made aware about puberty; consequently, many problems will arise in society with unaware teenagers. Therefore, it is suggested that mothers' knowledge about the experience and sanitation of puberty be improved.

\section{Authors' Contributions}

All authors contributed equally to this study.

\section{Conflict of Interest Disclosures}

No conflicts of interest are declared.

\section{Ethical Approval}

The current study was granted ethical permission from the Ethics Committee of the Vice-Chancellor of Research, Isfahan University of Medical Sciences, in June 2014.

\section{Research Highlights}

\section{What Is Already Known?}

The knowledge of mothers about puberty and its health issues is very important, especially for the better planning and necessary actions by the health system toward the empowerment of families.

\section{What This Study Adds?}

Overall, mothers' knowledge about health issues of puberty is acceptable. In different aspects of puberty, like the physical, nutritional, psychological, and social areas, more work needs to be done. Moreover, mother's education is an important factor in improving family health. Health managers can use the results of this study to focus more attention on the education of families in different areas of adolescent puberty.

\section{Funding/Support}

None received.

\section{Acknowledgments}

This thesis was for the MPH level of family doctor. The authors express their appreciation to the Research Deputy of Isfahan University of Medical Sciences for funding this project. The authors are also grateful to the secondary school managers, mothers, and health system personnel who cooperated in this research.

\section{References}

1. Moodi M, Zamanipour N, Sharifirad GR, Shahnazi H. Evaluating Puberty health program effect on knowledge increase among female intermediate and high school students in Birjand, Iran. J Educ Health Promot. 2013;2:57. doi:10.4103/2277-9531.120851.

2. Weissman $M M$, Wolk S, Wickramaratne $P$, et al. Children with prepubertal-onset major depressive disorder and anxiety grown up. Arch Gen Psychiatry. 1999;56(9):794-801. doi:10.1001/ archpsyc.56.9.794.

3. Reynolds BM, Juvonen J. Pubertal timing fluctuations across middle school: implications for girls' psychological health. J Youth Adolesc. 2012;41(6):677-690. doi:10.1007/s10964-011-9687-x.

4. Ahangrzadeh Rezaei S, Khalilzadeh $\mathrm{H}$. Enhancing management of mothers during adolescence of their daughters in guidance schools of Urmia. J Urmia Nurs Midwifery Fac. 2012;9(6):417423. [Persian].

5. The age group of 10-19 years. Tehran: Statistical Center of Iran; 2012. https://www.amar.org.ir/english.

6. Malek A, Shafiee-Kandjani AR, Safaiyan A, Abbasi-Shokoohi H. Sexual Knowledge among High School Students in Northwestern Iran. ISRN Pediatr. 2012;2012:645103. doi:10.5402/2012/645103.

7. Sexual and reproductive health. WHO website. http://www.who. int/reproductivehealth/publications/sexual_health/en/index.html.

8. Zabihi A. Effect of education on knowledge and practice of female students about puberty health. J Babol Univ Med Sci. 2002;4(3):5862. [Persian].

9. Kalantary S, Ghana S, Sanagoo A, Jouybari L. Puberty and sex education to girls: experiences of Gorganians' mothers. J Health Promot Manag. 2013;2(3):74-90.

10. Nouri M, Merghati khoie ES. The impact of peer-based educational approaches on girls' physical practice of pubertal health. Arak Med Univ J. 2010;12(4):129-135. [Persian]

11. Ahmadi F, Anoosheh M, Vaismoradi M, Safdari MT. The experience 
of puberty in adolescent boys: an Iranian perspective. Int Nurs Rev. 2009;56(2):257-263. doi:10.1111/j.1466-7657.2008.00670.x.

12. Majlessi F, Rahimi A, Mahmoudi M, Hosseinzadeh P. The impact of lecture and educational package methods in knowledge and attitude of teenage girls on puberty health. Bimonthly Journal of Hormozgan University of Medical Sciences. 2012;15(4):327-332. [Persian].

13. Alimordi Z, Simbar M. Puberty health education for Iranian adolescent girls: challenges and priorities to design school-based interventions for mothers and daughters. Payesh. 2014;13(5):621636. [Persian].

14. Golchin NAH, Hamzehgardeshi Z, Fakhri M, Hamzehgardeshi L. The experience of puberty in Iranian adolescent girls: a qualitative content analysis. BMC Public Health. 2012;12:698. doi:10.1186/1471-2458-12-698.

15. Najafi F, Mozafari S, Mirzaee S. Assessment of 3rd grade junior school girl students' knowledge and attitude toward puberty age sanitation. J Guilan Univ Med Sci. 2012;21(81):22-28. [Persian].

16. Karimi E. Investigate the attitude of mothers towards education of puberty problems in secondary school children, girls age between 11-14 years old. Iran J Nurs. 1998;12(18):74-79. [Persian].

17. Poushaneh K, Alavi M, Khosravi AA. Puberty health: knowledge, attitude and practice of the adolescent girls in Tehran, Iran. Payesh. 2009;8(1):59-65. [Persian].

18. Malek Afzali H, Jandaghi J, Allameh R, Zare M. Study of educational needs of 12-14 years old girls about adolescent health and determines appropriate and effective strategies for adolescent health education. Koomesh. 2000;1(2):39-47. [Persian].

19. Kazemi Z. The effect of family variables on information rate of guidance school female students about maturity health. J Fam Res. 2012;8(31):319-335. [Persian]. 